\title{
Revisiting Edge-Sites of $\boldsymbol{\gamma}-\mathrm{Al}_{2} \mathrm{O}_{3}$ Using Needle-
}

\section{Shaped Nanocrystals and Recoupling-Time Encoded}

\section{$\left\{{ }^{27} \mathrm{Al}\right\}-{ }^{1} \mathrm{H} D$-HMQC NMR Spectroscopy}

Laura A. Völker ${ }^{1+}$, Jordan Meyet ${ }^{* 1}$, Zachariah Berkson ${ }^{1}$, Lukas Rochlitz ${ }^{1}$, Jeroen A. van Bokhoven $^{* 1,2}$ and Christophe Copéret*1

${ }^{1}$ Department of Chemistry and Applied Biosciences, ETH Zürich, Vladimir Prelog Weg 1-5, CH8093 Zurich, Switzerland

${ }^{2}$ Laboratory for Catalysis and Sustainable Chemistry, Paul Scherrer Institute, 5232 Villigen, Switzerland

KEYWORDS NMR Spectroscopy, gamma-Alumina, Heterogeneous Catalysis

ABSTRACT: Despite being widely used in numerous catalytic applications, our understanding of reactive surface sites of high surface-area $\gamma-\mathrm{Al}_{2} \mathrm{O}_{3}$ remains limited to date. Recent contributions have pointed towards the potential role of highly reactive edge-sites contained in the high-field signal of the ${ }^{1} \mathrm{H}-\mathrm{NMR}$ spectrum of $\gamma-\mathrm{Al}_{2} \mathrm{O}_{3}$ materials. This work combines the development of needle-shaped $\gamma-\mathrm{Al}_{2} \mathrm{O}_{3}$ nanocrystals having a high relative fraction of edge sites with the use of state of art solid-state NMR $-{ }^{1} \mathrm{H}-{ }^{1} \mathrm{H}$ Single-Quantum (SQ) Double-Quantum (DQ) and ArbitraryIndirect-Dwell (AID) dipolar Heteronuclear Multiple Quantum Coherence ( $D$-HMQC) - to 
significantly deepen our understanding of this specific signal. We identify two distinct hydroxyl sites which possess altered isotropic chemical shifts, different positions within the dipole-dipole network and distinct proximities to different aluminum surface sites. Moreover, the use of recoupling-time encoded $D$-HMQC data allows us to partially revise previous assignments of $D$ HMQC data of $\gamma-\mathrm{Al}_{2} \mathrm{O}_{3}$ materials. While previous work has ascribed the high-field signal to be correlated to a single four-coordinate Al-site with substantial quadrupolar broadening we can identify the presence of two four-coordinate Al-sites with similar isotropic chemical shifts but different quadrupolar coupling constants. Recoupling-time-encoded data are thus able differentiate sites that would otherwise only be achievable with access to multiple fields or usage of highly advanced NMR techniques.

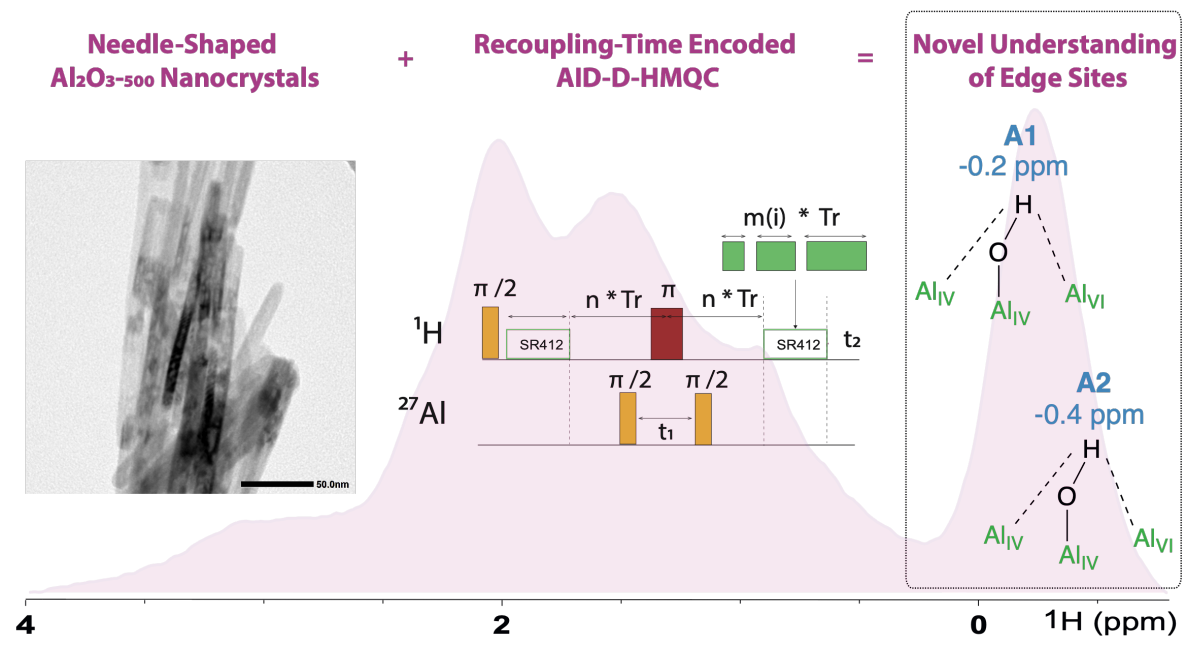

\section{INTRODUCTION}

Among all high surface area transitional alumina, the gamma-polymorph $\left(\gamma-\mathrm{Al}_{2} \mathrm{O}_{3}\right)$ has received an outstanding research interest within the last decades. Although being used in numerous catalytic applications, ${ }^{1}$ the bulk structure of $\gamma-\mathrm{Al}_{2} \mathrm{O}_{3}$ remains unsolved, limiting understanding of catalytically relevant surface sites such as reactive hydroxyl species or Lewis acidic aluminum 
centers becomes especially challenging. ${ }^{2}$ Density functional theory (DFT) calculations for surface sites of $\gamma-\mathrm{Al}_{2} \mathrm{O}_{3}$ emphasize the dependence of spectroscopic signatures on the relative exposure of specific crystal facets ${ }^{3,4,5}$ and thus the morphology of the studied $\gamma-\mathrm{Al}_{2} \mathrm{O}_{3}$ material. While these studies are mainly centered around the predominantly exposed (110),(100) and (111) facets, Busca and co-workers have pointed only recently towards the potential role of edge and corner sites, more specifically the $(100) /(110)$ edges, of $\gamma-\mathrm{Al}_{2} \mathrm{O}_{3}$ within this scheme ${ }^{6}$. In a combined experimental and computational work, Batista and co-workers provide further evidence for the presence of specific edge features by comparing the solid-state ${ }^{1} \mathrm{H}-\mathrm{NMR}$ magic angle spinning (MAS) spectra of two morphologically distinct $\gamma-\mathrm{Al}_{2} \mathrm{O}_{3}$ materials. ${ }^{7}$ These findings demonstrate the outstanding potential of NMR studies on $\gamma-\mathrm{Al}_{2} \mathrm{O}_{3}$ materials possessing well-defined morphologies with high edge-to-surface ratios to significantly broaden our understanding of $\gamma-\mathrm{Al}_{2} \mathrm{O}_{3}$ surface sites. As it dictates the final shape of the $\gamma-\mathrm{Al}_{2} \mathrm{O}_{3}$ material by topotactic transformation, controlling the boehmite growth is of prime importance and in the recent years, great advances have been made to better understand how parameters such as $\mathrm{pH}^{8-11}$ or ionic additives ${ }^{10,12-14}$ influence the morphology of boehmite crystallites. However, boehmite and thus $\gamma-\mathrm{Al}_{2} \mathrm{O}_{3}$ materials were previously mainly tailored towards exposure of specific facets, while little attention has been paid to their fraction of edge sites.

Here, a tailored $\gamma-\mathrm{Al}_{2} \mathrm{O}_{3}$ support with a needle-shaped morphology and thus high proportion of edge sites is prepared by using dodecanoic acid as a structure directing agent (SDA) during the synthesis of the Boehmite ( $\gamma-\mathrm{AlO}(\mathrm{OH}))$ material. As evidenced by IR and NMR spectroscopy, our support displays discrete $\mathrm{OH}$ groups including those that have been attributed to edge features. Using recoupling-time encoded and thus "pseudo-3-dimensional" $\left\{{ }^{27} \mathrm{Al}\right\}^{-1} \mathrm{H}$ Arbitrary-IndirectDwell dipolar Heteronuclear Multiple Quantum Coherence (AID $D$-HMQC) ${ }^{15}$ spectra enables us 
to refine the results of previous NMR studies on $\gamma-\mathrm{Al}_{2} \mathrm{O}_{3}$ materials and to further disentangle the components of broad aluminum signals without the need for advanced pulse sequence engineering or access to multiple magnetic fields. In combination with findings from ${ }^{1} \mathrm{H}-{ }^{1} \mathrm{H}$ Single-Quantum (SQ) Double-Quantum (DQ) spectroscopy, we can significantly deepen our understanding of the potential edge-sites of $\gamma-\mathrm{Al}_{2} \mathrm{O}_{3}$ by resolving two sites within the high-field signal and identifying surface-Al sites in their proximity. Overall, we demonstrate a robust yet simple methodology for the NMR characterization of pristine $\gamma-\mathrm{Al}_{2} \mathrm{O}_{3}$ materials and provide a novel basis for potential further computational and experimental studies.

\section{EXPERIMENTAL SECTION}

Experimental details of material preparation and solid-state NMR measurements are provided in the Supporting Information (Section S1 and S2).

\section{RESULTS AND DISCUSSION}

\section{Synthesis of Needle-Shaped $\gamma-\mathrm{Al}_{2} \mathrm{O}_{3}$ Nanocrystals}

With the aim to investigate the role of sites on the $(100) /(110)$ edge of alumina using solid-state NMR, the possibility of increasing the aspect ratio of hexahedral nanocrystals and thus the proportion of edge over surface sites was explored. In general, acidic conditions favor formation of hexahedral Boehmite nanorods while platelet-like morphologies are obtained in basic regimes. Ionic additives can further fine-tune these morphologies via adsorption and thus anisotropic suppression of crystal growth. A previous study employing long alkyl chain carboxylic acid as 
modifiers during the hydrothermal treatment of boehmite nanoparticles has shown the ability of carboxylic acid to suppress the growth along the shorter axis, namely the (010) and (001) facets of boehmite through surface capping ${ }^{13}$, generating narrow hexagonal shaped boehmite crystallites. In this work, building on previous studies, ${ }^{16}$ we chose dodecanoic acid as the long chain carboxylic acid $\left(\mathrm{C}_{12}\right)$ in combination with aluminum basic acetate as the aluminum source in a 0.5 molar ratio $\left(\mathrm{C}_{12} / \mathrm{Al}\right)$. Hydrothermal treatment performed at $160{ }^{\circ} \mathrm{C}$ for 48 hours, results in the formation of needle-shaped $\gamma-\mathrm{Al}(\mathrm{OOH})$, confirmed by powder XRD and TEM (Figure 1). This synthetic procedure provides a simple and robust route for the formation of homogeneously distributed needle shape $\gamma-\mathrm{Al}(\mathrm{OOH})$ nanocrystals. Further topotactic transformation of the material by calcination at high temperature and dehydroxylation at $500^{\circ} \mathrm{C}$ leads to the formation of morphologically defined, needle-shaped $\gamma-\mathrm{Al}_{2} \mathrm{O}_{3-500}$, a suitable candidate for in depth characterization of well-defined $\gamma-\mathrm{Al}_{2} \mathrm{O}_{3}$. We will refer to this material as Needle- $\mathrm{Al}_{2} \mathrm{O}_{3-500}$ throughout the following discussion. 
a)
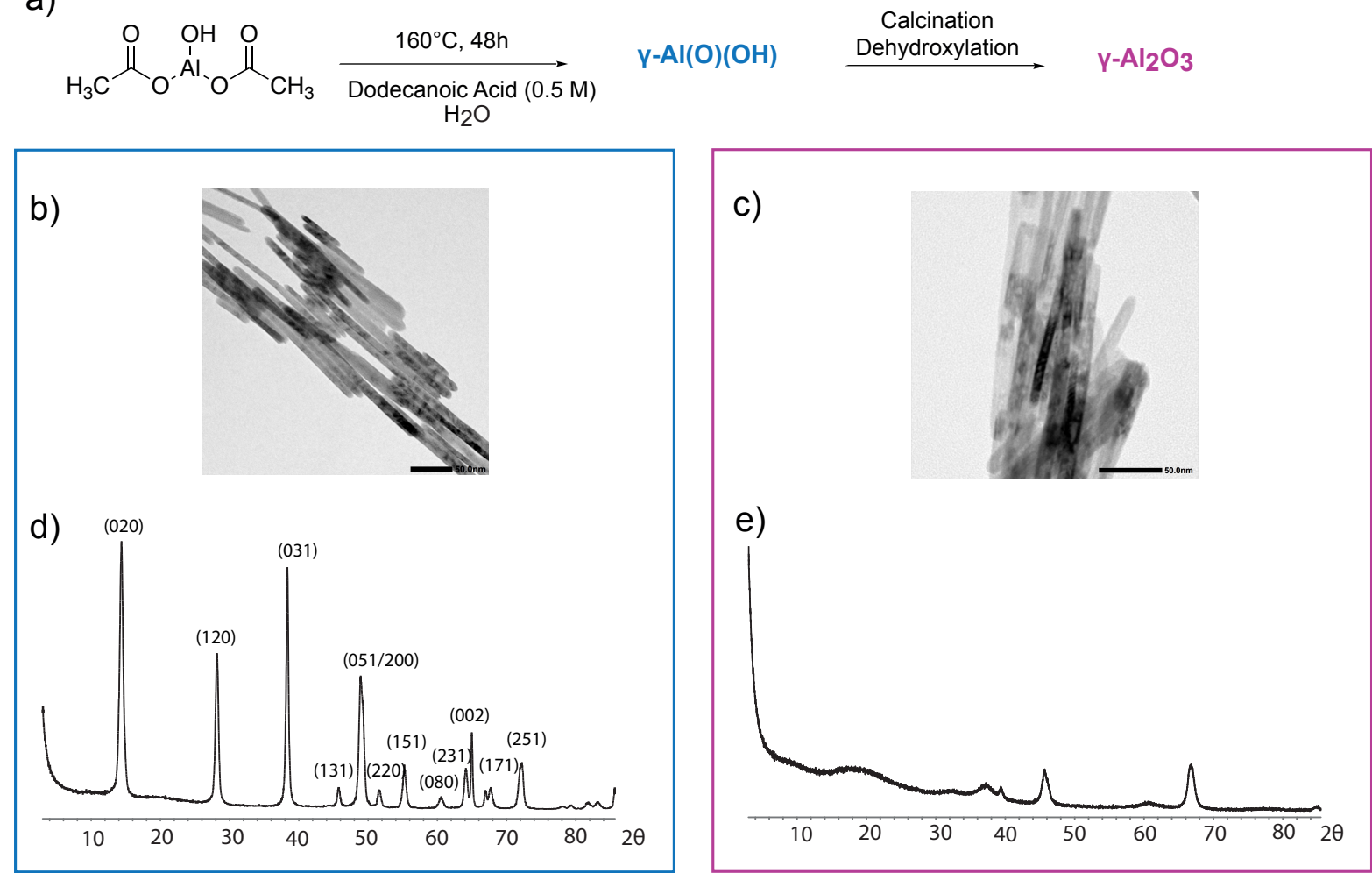

Figure 1. Crystal phase and morphology were verified at the boehmite $(\gamma-\mathrm{Al}(\mathrm{O})(\mathrm{OH}))$ stage $(\mathrm{b}$, d) and after calcination to $\gamma-\mathrm{Al}_{2} \mathrm{O}_{3}$ (c, e) using powder X-ray diffraction (P-XRD) and transmission electron microscopy (TEM). Since boehmite transforms into $\gamma-\mathrm{Al}_{2} \mathrm{O}_{3}$ in a topotactic manner, the needle-shaped morphology of the nanocrystals is retained upon calcination. For the P-XRD of Boehmite the miller indices of the respective crystal planes are indicated for the individual reflections to simplify comparison with the standard reflection pattern. The morphology was tailored by using dodecanoic acid in the synthesis (a) .

\section{$1 \mathrm{H} N \mathrm{NR}$ and IR Studies of Needle- $\mathrm{Al}_{2} \mathrm{O}_{3-500}$}

The structural homogeneity of Needle- $\mathrm{Al}_{2} \mathrm{O}_{3-500}$ manifests in relatively well-resolved ${ }^{1} \mathrm{H}$ solidstate NMR and FTIR signals from distinct types of surface facets and edge -OH sites. Specifically, 
the $1 \mathrm{H}$ NMR spectrum (20 kHz MAS, $16.4 \mathrm{~T}$ ) of Needle- $\mathrm{Al}_{2} \mathrm{O}_{3-500}$ exhibits a high-field signal at $0.2 \mathrm{ppm}(\mathrm{A})$, surprisingly well resolved features in the region spanning from 0.9 to approximately 2 ppm with peak intensities at $0.95 \mathrm{ppm}(\mathrm{B}), 1.55 \mathrm{ppm}(\mathrm{C})$ and $2.05 \mathrm{ppm}$ (D) and a broad shoulder above $2.5 \mathrm{ppm}$ (Figure 2a). In parallel, the IR spectrum (Figure 2b) also possesses several distinct features at 3722, 3758, 3728 and $3667 \mathrm{~cm}^{-1}$. Both ${ }^{1} \mathrm{H}$ NMR and IR spectroscopy are commonly used to distinguish the bridging state $\left(\mu_{1}-\mathrm{OH}\right.$ vs $\mu_{2}-\mathrm{OH}$ vs $\left.\mu_{3}-\mathrm{OH}\right)$ of the corresponding hydroxyl as well as its involvement in hydrogen bonding. The ${ }^{1} \mathrm{H}-\mathrm{NMR}$ spectra of $\gamma-\mathrm{Al}_{2} \mathrm{O}_{3}$ have generally been reported to consist of a high field signal around $-0.2 \mathrm{ppm}$, a broad signal at about $1.8 \mathrm{ppm}$ and a shoulder in the region between 3 and $4 \mathrm{ppm}^{7,17,18}$, which is consistent with the herein reported spectral signatures although the resolution of individual features in the $0.5-2.5 \mathrm{ppm}$ region is unique for Needle- $\mathrm{Al}_{2} \mathrm{O}_{3-500}$ and has not been reported previously. In earlier works from De Canio et al. ${ }^{17}$ and Taoufik et al. ${ }^{18}$ the high field signal is assigned to $\mu_{1}-\mathrm{OH}$ sites, the signals around 1.8 ppm to $\mu_{2}-\mathrm{OH}$ and the shoulder at 3-4 ppm is interpreted as $\mu_{3}-\mathrm{OH}$ or hydrogen bonded hydroxyls. The work of Batista et al. ${ }^{7}$ suggests an alternate assignment which accounts for edge sites and assigns the high field signal mostly to isolated $\mu_{1}-\mathrm{OH}$ sites on the edges of alumina crystallites with minor contributions of both free and H-bond acceptor species on the (111) surface. The signals between 1-3 ppm are assigned to non-isolated $\mu_{1}-\mathrm{OH}$ and $\mu_{2}-\mathrm{OH}$ sites free from $\mathrm{H}$-bonds on both the surfaces and the edges while the shoulder above $3 \mathrm{ppm}$ is attributed to $\mu_{1}-\mathrm{OH}$ and $\mu_{2^{-}}$ $\mathrm{OH}$ species involved in hydrogen bonding. The strong intensity for the signal at $-0.2 \mathrm{ppm}$ for our high edge-to-surface ratio Needle- $\mathrm{Al}_{2} \mathrm{O}_{3-500}$ is consistent with this recent assignment by Batista $e t$ $a l$. and corroborates our strategy of optimizing the synthesis towards a needle-shaped, high-aspectratio morphology for spectroscopic studies of potential edge sites. For the interpretation of IR data different models exist, for example the ones of Tsyganenko, Knözinger, Busca and Digne. ., 19-21 
While all models share the common trend of decreasing stretching frequencies $v(\mathrm{OH})\left(\mathrm{cm}^{-1}\right)$ with increasing acidity of the hydroxyls, resulting in the general trend $v\left(\mu_{1}-\mathrm{OH}\right) \geq v\left(\mu_{2}-\mathrm{OH}\right) \geq$ $v\left(\mu_{3}-\mathrm{OH}\right)$, they differ in their exact assignments of the reported features.

a)

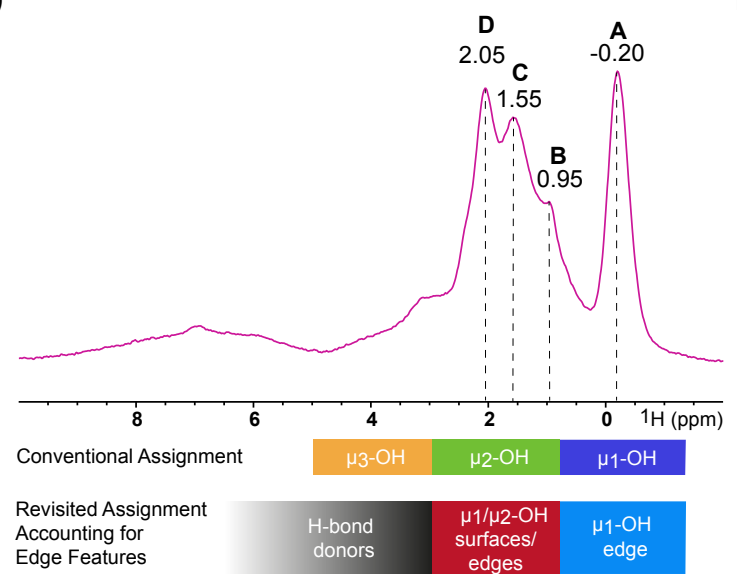

b)

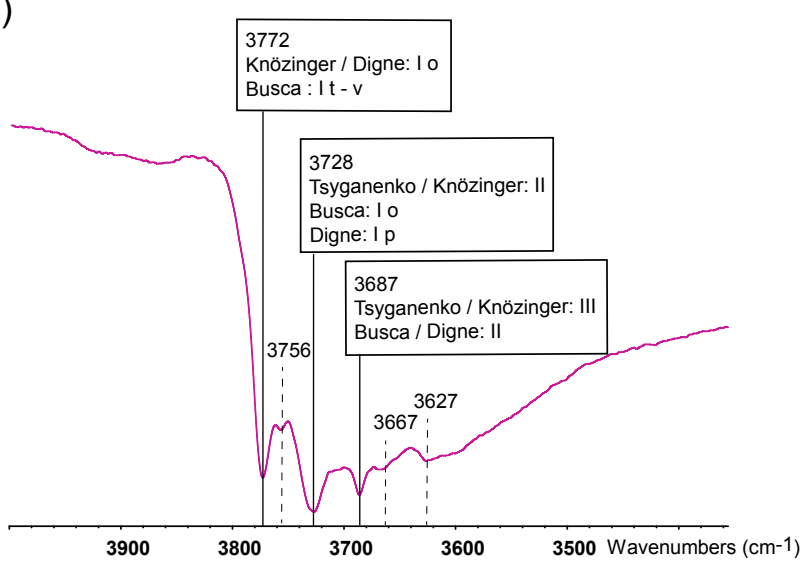

Figure 2. a) ${ }^{1} \mathrm{H}$ NMR spectrum of Needle- $\mathrm{Al}_{2} \mathrm{O}_{3-500}$ was acquired using a rotor synchronized echo with a 2 s recycle delay and echo delays spanning two rotor periods. In addition to an isolated signal at $-0.2 \mathrm{ppm}(\mathrm{A})$, features are resolved at $0.95 \mathrm{ppm}(\mathrm{B}), 1.55 \mathrm{ppm}(\mathrm{C})$ and $2.05 \mathrm{ppm}(\mathrm{D})$ in addition to a shoulder above $2.5 \mathrm{ppm}$. Conventional and more recent assignment strategies are indicated below the spectrum. b) IR spectrum of Needle- $\mathrm{Al}_{2} \mathrm{O}_{3-500}$ shown together with possible interpretations of the observed features based on various existing models (roman numerals (I, II, III) indicate bridging state of the hydroxyls, lower case letters $(\mathrm{v}, \mathrm{p}, \mathrm{o})$ indicate coordination environment of the Al-site(s) the hydroxyl is bound to).

To gain further insight into the nature of the hydroxyl sites we conducted studies on the ${ }^{1} \mathrm{H}$ longitudinal and transverse relaxation behavior. The results for the analysis of the longitudinal relaxation times $\left(\mathrm{T}_{1}\right)$ are summarized in the supporting information and were used to choose suitable recycle delays for $2 \mathrm{D}$ measurements. Due to the resemblance of the $\left\{{ }^{27} \mathrm{Al}\right\}-{ }^{1} \mathrm{H} D$-HMQC 
sequence to rotor-synchronized echo experiments on the proton channel we approximated the relevant relaxation behavior of the protons for the $D$-HMQC experiments by comparison with rotor synchronized echoes of varying echo delays instead of using the standard CPMG-technique for characterization of transversal $\left(\mathrm{T}_{2} / \mathrm{T}_{2}{ }^{*}\right)$ relaxation behavior. Indeed, the signals at $2.05 \mathrm{ppm}$ and $0.2 \mathrm{ppm}$ dominate the ${ }^{1} \mathrm{H}$ NMR spectra at prolonged echo delays while the signals at $1.5 \mathrm{ppm}$ and $0.95 \mathrm{ppm}$ as well as the shoulder above $2.5 \mathrm{ppm}$ are significantly reduced in intensity pointing towards reduced coherence lifetimes for these sites (Figure S4). As shortened coherence lifetimes can stem from various origins such as i) inclusion of the site in a dense dipolar coupling network ii) proximity of the site with a large quadrupolar coupling constant a clear interpretation of this finding is not possible. It is nevertheless detrimental to the acquisition of $\left\{{ }^{1} \mathrm{H}\right\}-{ }^{27} \mathrm{Al}$ D-HMQC experiments with different recoupling periods as these signals might decay upon prolonged recoupling.

Even though the ${ }^{1} \mathrm{H}$ NMR spectrum exhibits relatively well-defined features, it is very likely that these arise from distinct hydroxyl sites with overlapping ${ }^{1} \mathrm{H}$ chemical shifts. To further resolve potential species and to gain insights into their relative proximities we measured the $2 \mathrm{D}{ }^{1} \mathrm{H}-\left\{{ }^{1} \mathrm{H}\right\}$ SQ-DQ ${ }^{22,23}$ spectrum of Needle- $\mathrm{Al}_{2} \mathrm{O}_{3-500}$ (Figure 3). The spectrum overall parallels previous findings,$^{7,17,18}$ however the improved resolution provided by structurally defined alumina allows us to deepen the previous assignments. We can thus provide the following more detailed picture of the features of the ${ }^{1} \mathrm{H}$ NMR spectrum:

- The high field signal (A in figure 2) is not a single feature, but consists of at least two distinct groups with slightly differing isotropic chemical shifts of $-0.2 \mathrm{ppm}$ and $-0.4 \mathrm{ppm}$ that we will refer to as A1 and A2 in the following discussion. In addition to a strong selfcorrelating diagonal-peak at (-0.2 ppm, $-0.4 \mathrm{ppm})$ which seems to be dominated by signal 
A2, the 2D spectrum reveals additional correlations of signal A1 and signals at 1.9 and 3.2 ppm as well as an intense cross-correlation of signal A2 to a signal at $2.3 \mathrm{ppm}$. It is possible that multiple additional signals are further contained within A1 and A2; we will comment further on this in the following discussion.

- The region around $1.8 \mathrm{ppm}$ reveals at least five different signals at $0.95 \mathrm{ppm}, 1.3 \mathrm{ppm}, 1.6$ ppm, $1.9 \mathrm{ppm}$ and $2.3 \mathrm{ppm}$. The signals at $1.3 \mathrm{ppm}$ and $1.6 \mathrm{ppm}$ seem to be strongly correlated, as previously reported..$^{18}$ This is consistent with the observed short coherence lifetime for this region of the ${ }^{1} \mathrm{H}$ spectrum as well as the previous REDOR studies. ${ }^{18}$

- The shoulder around $3 \mathrm{ppm}$ reveals a correlation to the signal at $1.9 \mathrm{ppm}$ with no detectable self-correlations.

The most notable of these findings is the disentanglement of the high field signal into at least two different contributions, indicating the presence of two structurally similar yet distinct hydroxyl sites. Although not shown in this work, we could further verify this differentiation based on different reactivities of A1 and A2 sites towards an organometallic compound. Taking into account the most recent assignments for the high field signal of $\gamma-\mathrm{Al}_{2} \mathrm{O}_{3}$ to $\mu_{1}-\mathrm{OH}$ sites at edges $^{7}$ at least two distinct edge hydroxyl features with different local structures and correspondingly different dipole-dipole couplings to nearby $\mathrm{OH}$ species are present. One of these sites (A1) is in close proximity to other sites of the same type while the other site (A2) is mainly close to $\mu_{2}-\mathrm{OH}$ sites. 

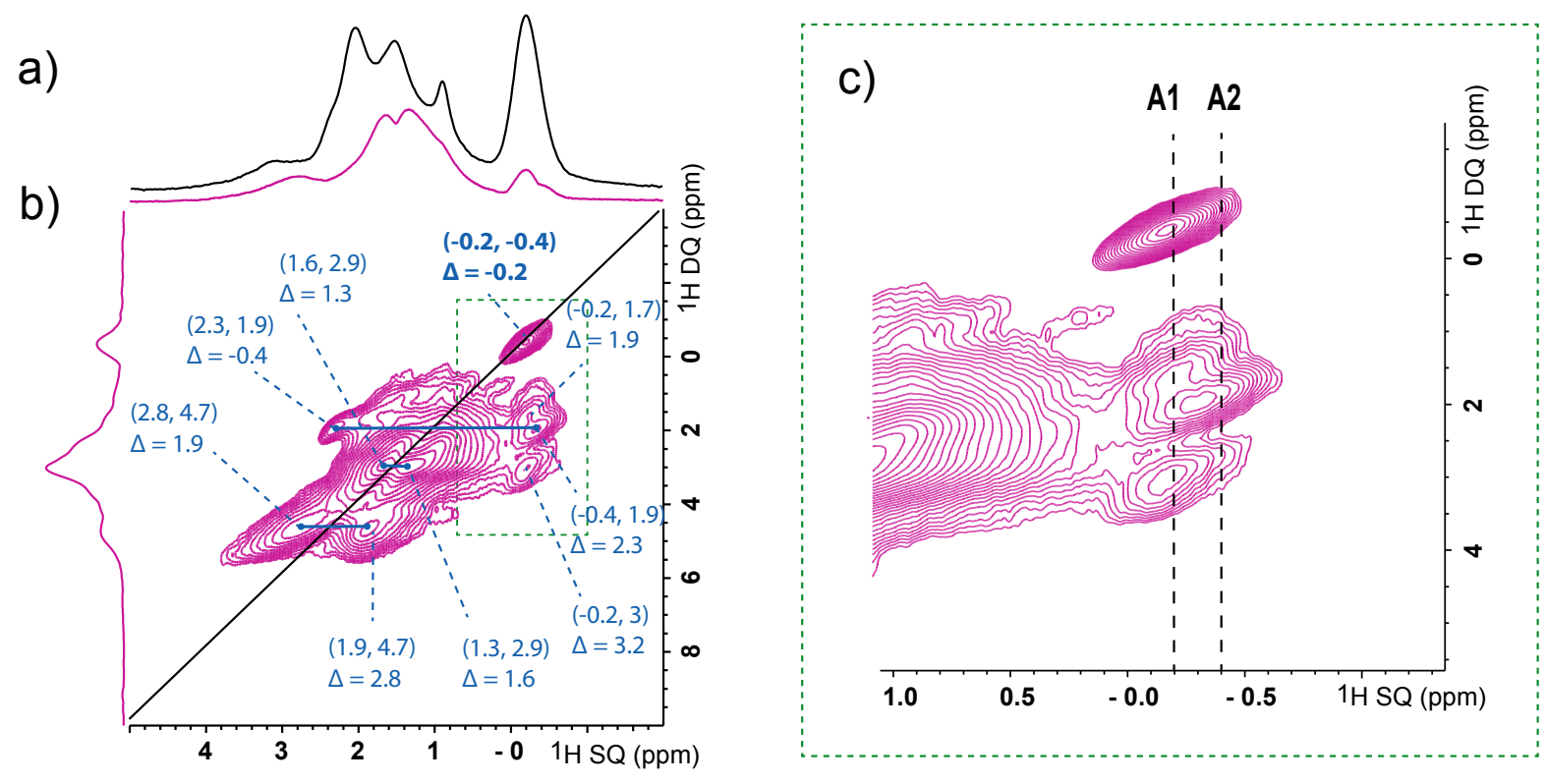

Figure 3. b) The ${ }^{1} \mathrm{H}-{ }^{1} \mathrm{H}$ SQ-DQ correlation ${ }^{22}$ spectrum of Needle- $\mathrm{Al}_{2} \mathrm{O}_{3-500}$ was acquired using one rotor period of $\mathrm{BaBa}$ recoupling ${ }^{23}$, a $2 \mathrm{~s}$ recycle delay and 768 scans for each of the $96 \mathrm{t}_{1^{-}}$ increments and is depicted together with the rotor synchronized echo (a) of Needle- $\mathrm{Al}_{2} \mathrm{O}_{3-500}$ that was acquired under analogous conditions (i.e. same rotor, same recycle delay). The spectrum is dominated by a strong self-correlation of the $-0.2 \mathrm{ppm}$ signal, and cross-correlations of the signals at 1.3 and $1.8 \mathrm{ppm},-0.4$ and $2.3 \mathrm{ppm}$ as well as 1.9 and $2.8 \mathrm{ppm}$. c) The high field signal (A) consists of two distinct hydroxyl sites with isotropic chemical shifts of -0.2 (A1) and -0.4 ppm (A2). The A1 sites reveal a strong self-correlation while the sites at -0.4 ppm reveal a correlation to the sites at $1.9 \mathrm{ppm}$.

\section{Recoupling-Time Encoded $\left\{{ }^{27} A l\right\}^{-1} H$ D-HMQC NMR Spectroscopy}

To further understand the nature of the newly resolved hydroxyl features we turned towards $\left\{{ }^{27} \mathrm{Al}\right\}-{ }^{1} \mathrm{H} D$-HMQC spectroscopy. $D$-HMQC experiments are a robust technique to investigate heteronuclear correlations between protons and quadrupolar nuclei and are suited for NMR studies of alumina materials. ${ }^{24-26}$ For the present study we decided to employ $\left\{{ }^{27} \mathrm{Al}\right\}-{ }^{1} \mathrm{H}$ type experiments 
in which polarization is initially transferred from protons to surrounding ${ }^{27} \mathrm{Al}$ nuclei and then backtransferred for proton-detection to obtain increased sensitivity and a high resolution in the proton dimension. In cases where the proton relaxation times significantly exceed those of the ${ }^{27} \mathrm{Al}$ species, the reverse $\left\{{ }^{1} \mathrm{H}\right\}-{ }^{27} \mathrm{Al}$ scheme might be preferrable. ${ }^{26}$ Two important characteristics of the $D$-HMQC experiment are the chosen recoupling method and the scheme for time incrementation in the indirect dimension of the experiment. As it has been reported to be a very versatile and robust technique, ${ }^{27}$ we have decided to use the $\mathrm{SR} 4{ }_{1}{ }^{2}$ recoupling sequence, ${ }^{28}$ an $\mathrm{R}$-type rotor synchronized recoupling sequence and a super-cycled version of the basic $\mathrm{R} 4_{1}{ }^{2}$ sequence. In order to minimize relaxation losses in the indirect dimension we employ the arbitrary indirect dwell (AID) variant of the $D$-HMQC experiment that has been introduced recently by Venkatesh $e t$ al. ${ }^{8}$ The incrementation protocol is such that the echo period on the ${ }^{1} \mathrm{H}$ channel is not constant (CT $D$ HMQC) but rather the minimum multiple of rotor periods compatible with the current time increment. 
a)

Previous Works:

D-HMQC at Fixed Recoupling Times
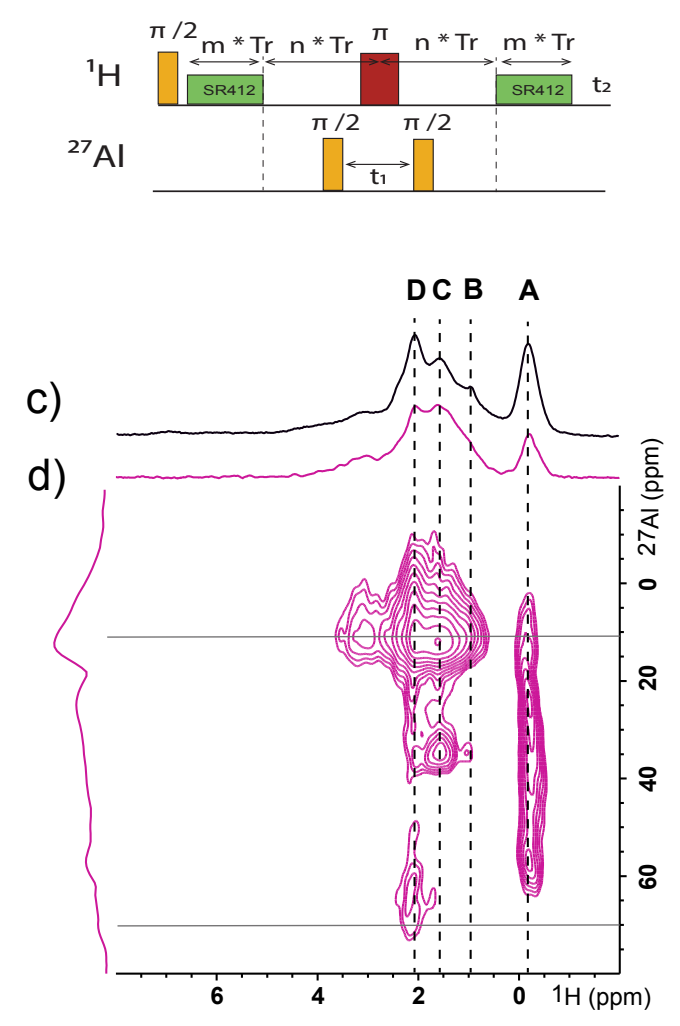

b) This Work:

Recoupling-Time Encoded D-HMQC

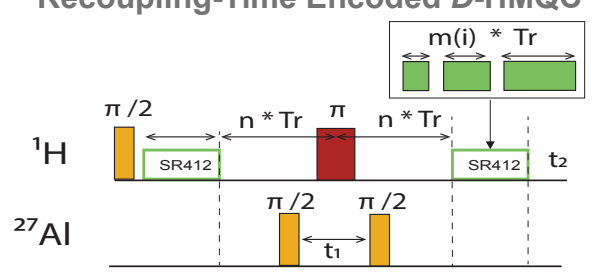

e)

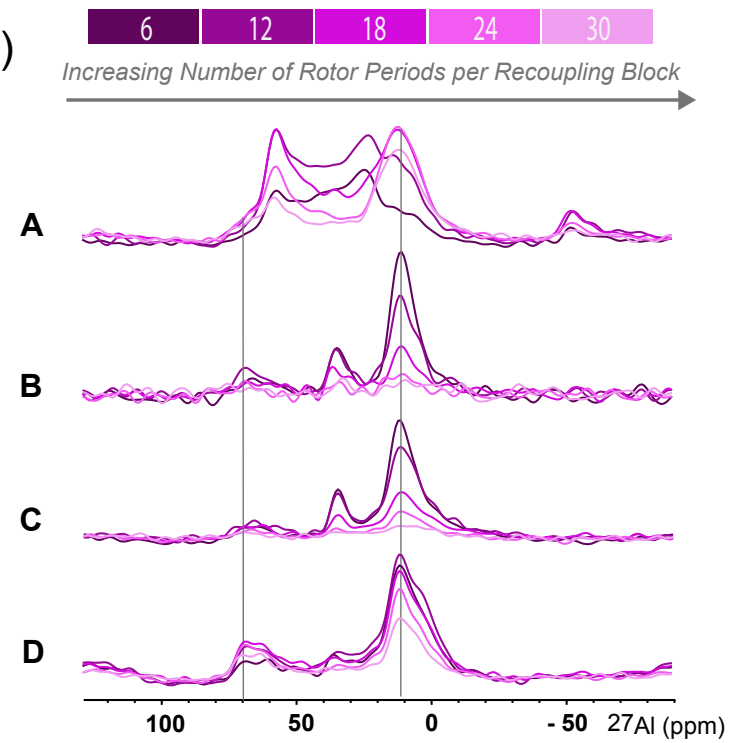

Figure 4. a) In previous studies ${ }^{1} \mathrm{H}-{ }^{27} \mathrm{Al}$ correlations of $\gamma-\mathrm{Al}_{2} \mathrm{O}_{3}$ materials were determined based on a single $D$-HMQC experiment with a fixed recoupling length that is typically chosen as short as possible to remain selective for surface over bulk species. b) In this work, we encourage acquisition of a series of $D$-HMQC experiments with different recoupling lengths to differentiate a single quadrupolar broadened site from multiple species. c) The ${ }^{1} \mathrm{H}$ NMR spectrum of Needle$\mathrm{Al}_{2} \mathrm{O}_{3-500}$ was acquired using a rotor synchronized echo with echo-periods spanning six rotor periods and a recycle delay of $2 \mathrm{~s}$ in order to simulate the relaxation behavior present in the $2 \mathrm{D}$ spectrum below. All features that could be identified in the fully relaxed ${ }^{1} \mathrm{H}$ NMR spectrum at short echo delays remain present to a sufficient extent to be detected in the $2 \mathrm{D}$ experiment. $\mathrm{d}$ ) AID-D-HMQC spectrum of Needle-Al2O 3 using six rotor periods of SR $4_{1}^{2}$ recoupling. 
Chemical shifts of the main features (A, B, C, D) of the 1H NMR spectrum are indicated with dashed lines, intensity maxima of aluminum signals obtained from direct excitation aluminum measurements are indicated with solid lines. The spectrum reveals a broad correlation of the ${ }^{1} \mathrm{H}$ signal A with ${ }^{27} \mathrm{Al}$ signals spanning from 10 to $70 \mathrm{ppm}$. For the remaining features of the ${ }^{1} \mathrm{H}$ NMR spectrum correlations to three types of aluminum signals are detected, corresponding to ${ }^{27} \mathrm{Al}$ sites with different coordination numbers $\mathrm{Al}_{\mathrm{IV}}, \mathrm{A}_{\mathrm{V}}$ and $\mathrm{Al}_{\mathrm{VI}}$. e) Calculated ${ }^{27} \mathrm{Al}$ projections of AID-D-HMQC spectra at different recoupling times are for sites A,B, C and D. The color of the projections encodes the recoupling length that was used in the respective $2 \mathrm{D}$ experiment, ranging from 6 (dark purple) to 30 (light pink) rotor periods. While for species B, C and D no additional insights can be gained using this strategy, it allows to revisit the assignment of the signal A. One can differentiate three different contributions to the signal. The ${ }^{27} \mathrm{Al}$ species giving rise to the signal maximum around 20 ppm disappears quickly upon prolonged recoupling time and therein reveals two additional underlying signals.

Previously, 2D ${ }^{1} \mathrm{H}-{ }^{27} \mathrm{Al}$ correlations of $\gamma-\mathrm{Al}_{2} \mathrm{O}_{3}$ materials were analyzed on the basis of a single 2D $D$-HMQC experiment with a fixed recoupling length spanning $m$ rotor periods (for SR $4_{1}{ }^{2}$ recoupling $m=6,12,24 \ldots)$ that is typically chosen as short as possible to remain selective for surface over bulk species (Figure $4 \mathrm{a}$ ). The acquisition of a single $\left\{{ }^{27} \mathrm{Al}\right\}-{ }^{1} \mathrm{H} D$-HMQC spectrum for Needle- $\mathrm{Al}_{2} \mathrm{O}_{3-500}$ using six rotor periods of $\mathrm{SR} 4_{1}{ }^{2}$ recoupling $(m=6)$ reproduces previous findings (Figure 4c). Different ${ }^{27} \mathrm{Al}$ signals corresponding to ${ }^{27} \mathrm{Al}$ species in 6,5 or 4 -coordinate environments $\left(\mathrm{Al}_{\mathrm{VI}}, \mathrm{Al}_{\mathrm{V}}\right.$ or $\mathrm{Al}_{\mathrm{IV}}$, respectively) are resolved on established correlations between coordination number of the aluminum site and its chemical shift ${ }^{29}$. In figure $4 \mathrm{~d}$, each of the ${ }^{1} \mathrm{H}$ 
signals $\mathrm{B}, \mathrm{C}$ and $\mathrm{D}$ are correlated to resolved are correlated to resolved ${ }^{27} \mathrm{Al}$ signals from $\mathrm{Al}_{\mathrm{VI}}$, $\mathrm{Al}_{\mathrm{v}}$, and $\mathrm{Al}_{\mathrm{IV}}$, consistent with the presence of multiple types of hydroxyls bridging between aluminum sites of different coordination number. The shoulder above $3 \mathrm{ppm}$ is solely coordinated to $\mathrm{Al}_{\mathrm{IV}}$ species. By comparison, ${ }^{1} \mathrm{H}$ signal $\mathrm{A}$ is correlated to a very broad ${ }^{27} \mathrm{Al}$ feature between 10 and $70 \mathrm{ppm}$. However, it is not possible to fully deconvolute this feature on the basis of a single such measurement due to the complex quadrupolar lineshapes of ${ }^{27} \mathrm{Al}$ signals, particularly for species with large $\mathrm{C}_{\mathrm{Q}}$ such as surface sites. Even taking into account an additional measurement at a second magnetic field strength, it is not possible to fully discriminate multiple signals from a single and quadrupolar broadened spectral feature. For further insights into the nature of the surface edge sites that give rise to these correlated intensities, an additional dimension of information is required. "Pseudo-three-dimensional" NMR experiments can be obtained with relative ease by acquiring a series of the same twodimensional NMR spectra while varying a specific parameter. This parameter can be either an external factor, e.g. the temperature ${ }^{30}$ or a characteristic of the actual NMR experiment. In analogy to variable contact time CP experiments in biological NMR we decided to acquire a series of $D$-HMQC spectra with varying duration of the $\mathrm{SR} 4_{1}^{2}$ recoupling length spanning $m(i)=$ $6,12,24,18$ and 30 rotor periods respectively (Figure $4 b$ ). To the best of our knowledge, this strategy of "recoupling-time encoded" $D$-HMQC has not been employed to study surface species of alumina materials up to date even though for the studies of surface species the chosen recoupling time is an especially critical parameter as it determines the selectivity for surface over bulk signals.

The intensity variation of the observed correlations over the different recoupling times (Figure 4d) is a function of two main factors: i) the distance between the proton and the ${ }^{27} \mathrm{Al}$ site as the 
transfer is mediated via the heteronuclear dipole-dipole coupling and ii) the relaxation of the magnetization during the recoupling. Unfortunately, these effects cannot be fully disentangled. As discussed earlier one may slightly correct for occurring relaxation via comparison with rotor synchronized echoes at similar overall echo delays (e.g. comparing a 6-rotor-periods echo delay echo with a 6-rotor periods recoupling $D$-HMQC) but since relaxation behavior under free evolution and recoupling pulses are not necessarily identical this is a rather crude approximation. However, a full disentanglement of these concurring effects is not necessary for our further analysis as we do not aim at the extraction of specific distances but rather want to use the recoupling-encoded data to distinguish different ${ }^{27} \mathrm{Al}$ resonances that underly the broad feature. For a first analysis we focus on species A, B, C and D and do not further distinguish the additional sites that could be separated based on the proton correlation data. Regarding the B, C and D signals the benefit of the recoupling-time-encoded $D$-HMQC is less pronounced as these signals are already relatively well resolved using a single $D$-HMQC spectrum with fixed recoupling length. While the correlations for B and C disappear quickly upon increasing recoupling times, signal D reveals pronounced correlations even at 30 rotor periods of SR $4_{1}^{2}$ recoupling. The decay rates parallel our initial analysis of rotor synchronized echoes. For signals B, C and D and the shoulder above $2.5 \mathrm{ppm}$ we extracted isotropic chemical shifts $\delta_{i s o}$ and quadrupolar coupling constants $C_{Q}$ of the correlated Al sites using solely the spectrum with $m=6$ rotor periods recoupling and a second data set at comparable acquisition parameters but elevated magnetic field strength of $20 \mathrm{~T}$ for a best fit of sites with substantial gaussian line broadening. The $\mathrm{Al}_{\mathrm{IV}}$ sites can be modelled using $\delta_{i s o}=72 \mathrm{ppm}, C_{Q}=7 \mathrm{MHz}, \mathrm{Al}_{\mathrm{V}}$ sites with $\delta_{i s o}=44 \mathrm{ppm}, C_{Q}=7 \mathrm{MHz}$ and $\mathrm{Al}_{\mathrm{VI}}$ sites as $\delta_{i s o}=$ $16 \mathrm{ppm}, C_{Q}=6 \mathrm{MHz}$. These values are similar to those extracted by Taoufik et al. based on Czjzek- 
type models and differ mainly in the $C_{Q}$ values for $\mathrm{Al}_{\mathrm{IV}}$ and $\mathrm{Al}_{\mathrm{V}}$ sites which were reported to be around $12 \mathrm{MHz}$ instead of $7 \mathrm{MHz}$ in their study ${ }^{18}$.

The advantages of the recoupling-time encoded data set reveal themselves in the intensity variation for the ${ }^{27} \mathrm{Al}$ signals that are correlated to ${ }^{1} \mathrm{H}$ signal $\mathrm{A}$, which undergo a much more complicated evolution of the line-shape as a function of the chosen recoupling duration. A more detailed analysis for the newly differentiated A1 and A2 sites reveals that at least three different ${ }^{27} \mathrm{Al}$ signals are contained within their calculated ${ }^{27} \mathrm{Al}$ projections. First, there is a broad ${ }^{27} \mathrm{Al}$ signal with an intensity maximum at 20-30 ppm, which decays quickly upon prolonged recoupling delays. There are two additional narrower ${ }^{27} \mathrm{Al}$ signals with intensity maxima at approximately $60 \mathrm{ppm}$ and $11 \mathrm{ppm}$ that build up towards prolonged recoupling durations. Similar signals are observed for both $\mathrm{A} 1$ and $\mathrm{A} 2$, however the position of the ${ }^{27} \mathrm{Al}$ intensity maxima for the broad correlated signal differs slightly. For both, A1 and A2, we conducted a very simple line shape analysis of their correlated ${ }^{27} \mathrm{Al}$ signals using three different ${ }^{27} \mathrm{Al}$ sites each with significant gaussian line broadening (Table S1, Table S2, Figure 5). Again, the exact NMR parameters for the individual sites were chosen based on a comparison with additional data sets recorded at elevated magnetic field strength of $20 \mathrm{~T}$ but otherwise similar conditions (Figure S7). Keeping the NMR parameters constant while only varying the relative weights of the sites we are able to reproduce the observed linesshapes of the ${ }^{27} \mathrm{Al}$ projections for the $\mathrm{A} 1$ and $\mathrm{A} 2$ signals over a series of recoupling times. Remaining deviations between simulated and experimental line-shapes could stem from: i) slightly altered NMR parameters, ii) additional presence of minor species, or iii) the necessity for a Czjzek-type noise ${ }^{31}$ instead of a Gaussian broadening. Taking into account data sets which were acquired at different recoupling lengths, the low field end of the ${ }^{27} \mathrm{Al}$ projections cannot be modelled by a single quadrupolar broadened 
$\mathrm{Al}_{\mathrm{IV}}$ species. In contrast to previous assignments which describe the presence of a single $\mathrm{Al}_{\mathrm{IV}}$ species with $\delta_{i s o}=69 \mathrm{ppm}, C_{Q}=11.5 \mathrm{MHz}^{26}$, we interpret the low field end as two separate $\mathrm{Al}_{\mathrm{IV}}$ sites with similar isotropic shifts around $72 \mathrm{ppm}$ but different quadrupolar coupling constants of approximately 8 and $13.5 \mathrm{MHz}$ for $\mathrm{A} 1$ and 7 and $11.75 \mathrm{MHz}$ for $\mathrm{A} 2$. In addition, we can confirm the presence of $\mathrm{Al}_{\mathrm{VI}}$ sites with chemical shifts of roughly $19 \mathrm{ppm}$ and quadrupolar coupling constants around $6 \mathrm{MHz}$ for both $\mathrm{A} 1$ and $\mathrm{A} 2$. For both, $\mathrm{A} 1$ and $\mathrm{A} 2$, the $\mathrm{Al}_{\mathrm{IV}}$ site with the largest quadrupolar coupling constant decays faster and is only observable at short recoupling times while the other sites persist in the spectrum upon prolonged recoupling periods. As already pointed out by Wischert et al., sites with very large $C_{Q}$ values might simply be invisible due to their inherent reduced sensitivity as well as insufficient coherence lifetimes. ${ }^{29}$ The small $C_{Q}$ values of some sites could either result from very specific surface geometries, might be related to dynamics since all our spectra have been acquired at room-temperature or could point towards a sub-surface rather than surface nature of these sites. 


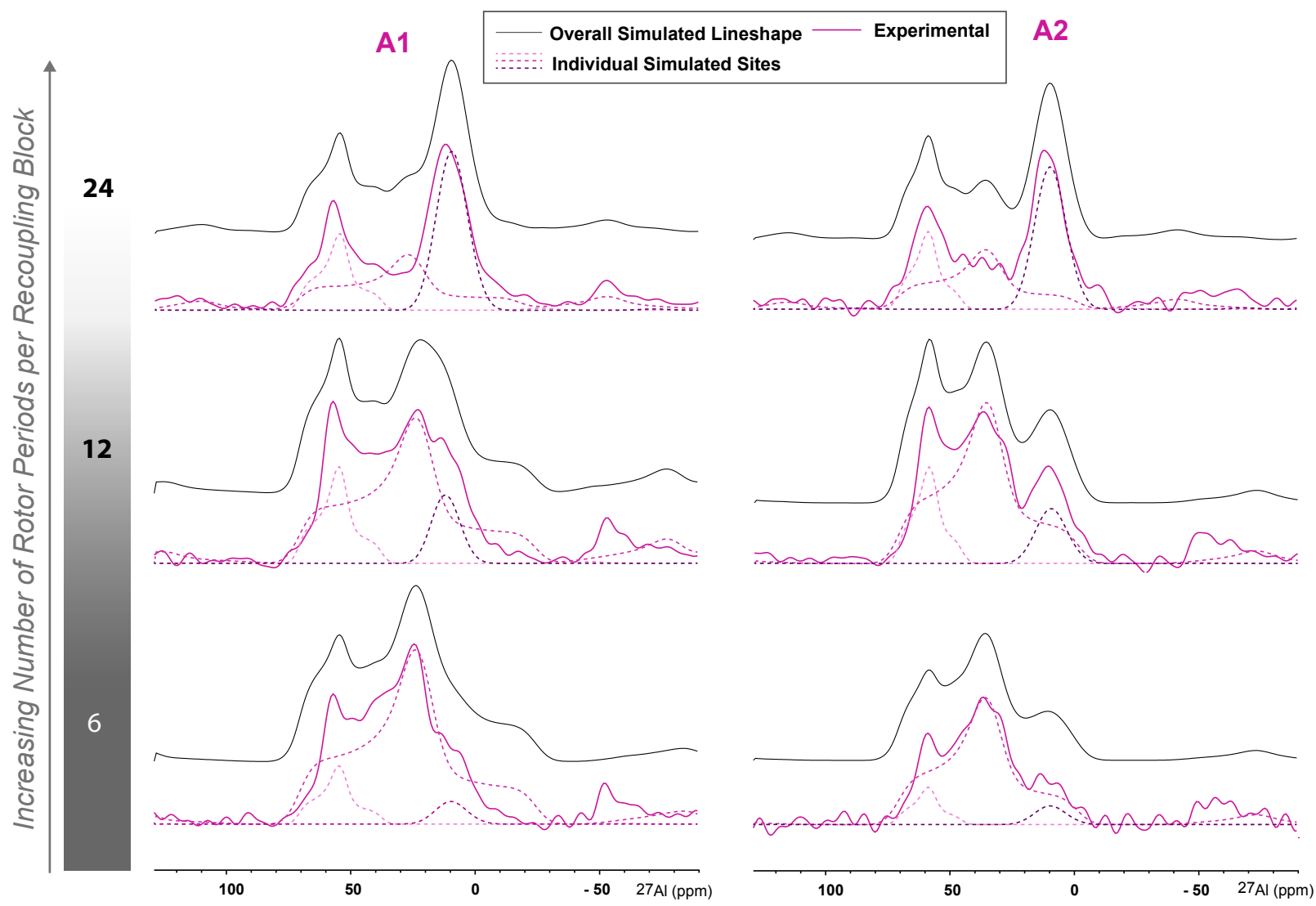

Figure 5. Simulated line shapes (black lines) for calculated ${ }^{27} \mathrm{Al}$ projections (solid pink lines) of A1 (left) and A2 (right) signals for AID-D-HMQC spectra with recoupling lengths of 6,12 and 24 rotor periods (from bottom to top). Three distinct ${ }^{27} \mathrm{Al}$ signals each (dashed lines) were used for A1 and A2 to simulate the spectra. The ${ }^{27} \mathrm{Al}$ NMR parameters of the signals were kept constant for the spectra at different recoupling times while the relative intensities of the sites were varied in order to follow the evolution of the line-shapes. Broad ${ }^{27} \mathrm{Al}$ signals from $\mathrm{Al}_{\mathrm{IV}}$ sites dominate the spectra at short recoupling times while narrower ${ }^{27} \mathrm{Al}$ signals from $\mathrm{Al}_{\mathrm{IV}}$ and $\mathrm{Al}_{\mathrm{VI}}$ sites build up towards longer recoupling times. Usage of recoupling-time encoded $D$ HMQC data thus allows the differentiation of multiple overlaying signals. 
To conclude, the potential edge sites that give rise to ${ }^{1} \mathrm{H}$ signals $\mathrm{A} 1$ and $\mathrm{A} 2$ possess similar but not fully identical ${ }^{27} \mathrm{Al}$ correlation patterns which further supports the distinct nature of the sites. Both $\mathrm{A} 1$ and $\mathrm{A} 2$ sites appear to be in proximity to $\mathrm{Al}_{\mathrm{IV}}$ surface sites with significant quadrupolar coupling constants $C_{Q}>10 \mathrm{MHz}$. If one assumes that A1 and A2 are indeed $\mu_{1}-\mathrm{OH}$ sites and therefore only bound to a single aluminum surface site, two different interpretations are possible for the additional correlations to the small- $C_{Q} \mathrm{Al}_{\mathrm{IV}}$ as well as $\mathrm{Al}_{\mathrm{VI}}$ sites. If one interprets $\mathrm{A} 1$ and $\mathrm{A} 2$ as a single type of hydroxyl each, the second $\mathrm{Al}_{\mathrm{IV}}$ as well as the $\mathrm{Al}_{\mathrm{VI}}$ site have to be either subsurface species or surface sites which are in the further surroundings of A1 and A2 but not directly bound to them. However, one should not exclude the possibility that further sites which are not resolved in the ${ }^{1} \mathrm{H}-{ }^{1} \mathrm{H}$ SQ-DQ spectrum are contained in A1 and A2. In this case additional scenarios are possible, e.g. one of these sites could be correlated to the large- $\mathrm{C}_{\mathrm{Q}}$ site and the second one to the small- $\mathrm{C}_{\mathrm{Q}}$ site. Based on our experimental data we cannot advocate one interpretation over the other, but we hope that our work will be taken as an input for further computational studies which might have the potential to allow for an unambiguous interpretation. 


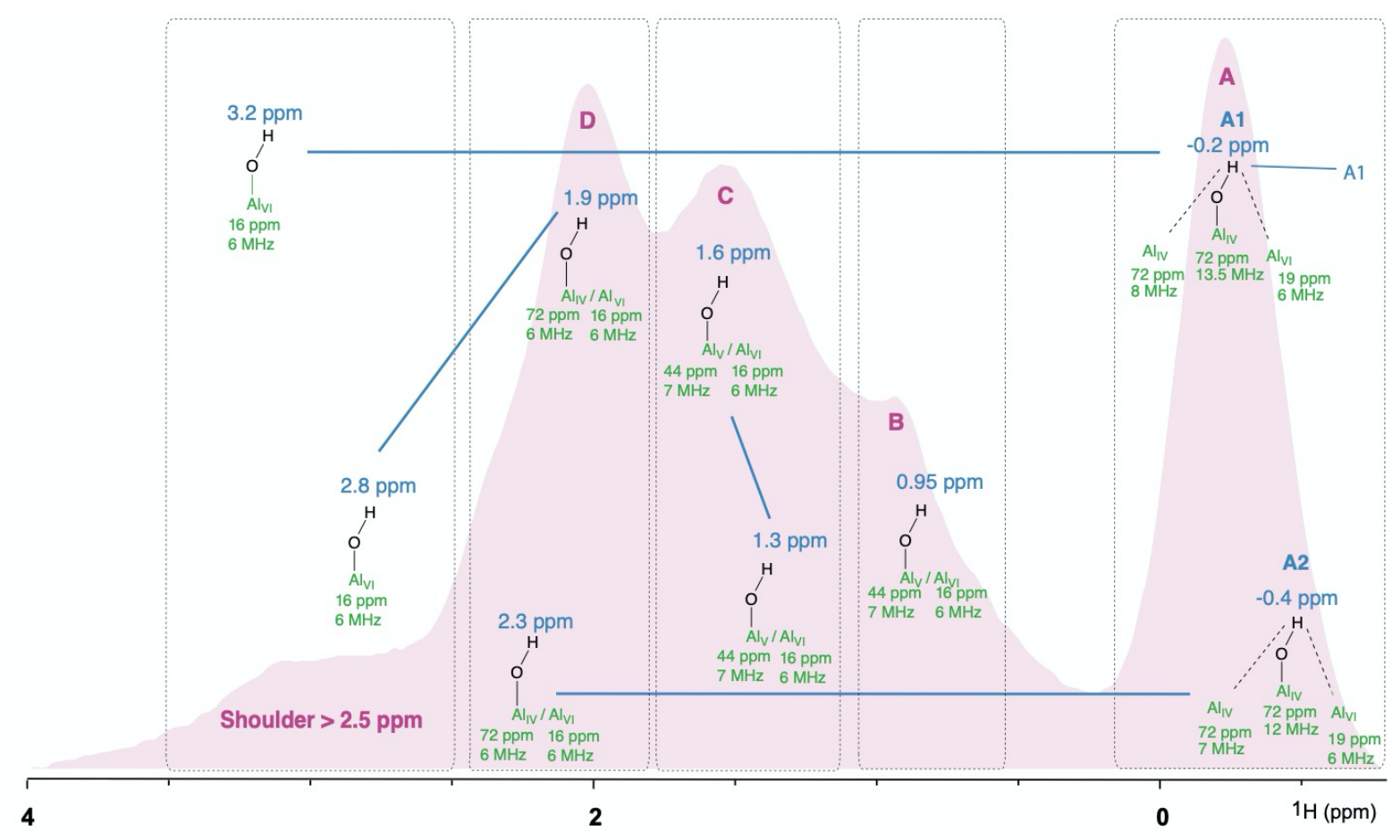

Figure 6. Summary of novel structural insights that are obtained in our in our in-depth spectroscopic analysis of a well-defined $\gamma-\mathrm{Al}_{2} \mathrm{O}_{3}$ material: Features that could be identified in the 1H-1H SQ-DQ correlation experiment (blue) with their respective relative proximities (blue lines) are grouped into the broader features that can be distinguished already from the $1 \mathrm{D}{ }^{1} \mathrm{H}$ NMR Spectrum (pink). For all species ${ }^{27} \mathrm{Al}$ sites to which correlations are visible in $D$-HMQC experiments are indicated (green). Please note that for improved visibility the bridging character of the hydroxyls is not indicated, especially those that are contained ingroups B, C and D may be $\mu_{2}-\mathrm{OH}$.

\section{Conclusion}

Using a well-defined tailored $\gamma-\mathrm{Al}_{2} \mathrm{O}_{3}$ material with a large abundance of edge sites and highly resolved signals in both IR and NMR in combination with state-of-the-art 2D and pseudo-3D solidstate NMR spectroscopy, we went beyond established NMR studies on $\gamma-\mathrm{Al}_{2} \mathrm{O}_{3}$, more specifically the high-field ${ }^{1} \mathrm{H}-\mathrm{NMR}$ signal that has been in the focus of recent interest due to its potential link 
to highly reactive edge sites. The combined results of our NMR analysis and the structural implications are summarized in Figure 6, including all distinct hydroxyl sites and relative proximities that we could identify based on $1 \mathrm{D}$ and $2 \mathrm{D}$ measurements as well as the NMR parameters of the ${ }^{27} \mathrm{Al}$ sites to which they are correlated. Overall, the high homogeneity of our alumina material has allowed us to reveal a variety of distinct hydroxyl sites that could not been resolved beforehand. Most importantly, from 2D ${ }^{1} \mathrm{H}-\left\{{ }^{1} \mathrm{H}\right\}$ SQ-DQ NMR spectroscopy we can show that the ${ }^{1} \mathrm{H}$ NMR signal which has been the subject of recent investigations and edge-theories in fact corresponds to at least two distinct hydroxyl sites with different local environments and proximities to surface $-\mathrm{OH}$ and $\mathrm{Al}$ sites. These differences manifest in distinct ${ }^{1} \mathrm{H}$ chemical shifts, and different correlations in the $2 \mathrm{D}^{1} \mathrm{H}-{ }^{1} \mathrm{H}$ and ${ }^{1} \mathrm{H}-{ }^{27} \mathrm{Al}$ correlation spectra. Using recoupling-time encoded $\left\{{ }^{27} \mathrm{Al}\right\}-{ }^{1} \mathrm{H}$ D-HMQC spectra, we were furthermore able to go beyond previous interpretations of the ${ }^{27} \mathrm{Al}$ projections for the high field signal which seems to contain more sites than accounted for in earlier works. Since our strategy circumvents measurements at different magnetic fields or application of further advanced NMR techniques to separate ${ }^{27} \mathrm{Al}$ signals based on their different quadrupolar coupling strengths, it might be especially useful for more synthetically-oriented groups which do not have access to multiple high field magnets or a variety of such pulse sequences.

The methodology presented here has the potential to improve structural assignments and provide experimental constraints for refining computational models of surface species, not just for catalytic materials based on $\gamma-\mathrm{Al}_{2} \mathrm{O}_{3}$, but also for other functional materials with complex surface structures. Our work also serves as an important demonstration on the synergetic effects of combined efforts of materials research and NMR spectroscopy. We hope that the herein presented methodology inspires further work, not only on $\gamma-\mathrm{Al}_{2} \mathrm{O}_{3}$ materials with different well-defined morphologies and 
tailored surface chemistries but also on other functional materials containing complicated lineshapes due to the presence of multiple overlapping broadened sites. We also advocate that recoupling-time encoded $\left\{{ }^{27} \mathrm{Al}\right\}-{ }^{1} \mathrm{H} D$-HMQC NMR studies should be pursued on a broad range of $\gamma-\mathrm{Al}_{2} \mathrm{O}_{3}$ materials in order to evaluate the presence of multiple $\mathrm{Al}_{\mathrm{IV}}$ species.

\section{ASSOCIATED CONTENT}

\section{Supporting Information.}

The following files are available free of charge:

Experimental details on materials preparation and solid-state NMR measurements, additional TEM data, additional NMR spectra, numerical values for line shape analysis (PDF)

\section{AUTHOR INFORMATION}

\section{Corresponding Author}

* Christophe Copéret: ccoperet@ethz.ch

* Jeroen A. van Bokhoven, jeroen.vanbokhoven@chem.ethz.ch

\section{Present Addresses}

$†$ Department of Physics, Laboratory for Solid-State Physics, ETH Zürich, 8093 Zürich, Switzerland

\section{Author Contributions}

$\$$ These authors contributed equally. J.M developed the synthesis route to Needle A12O3-500. L.V. and J.M synthesized all molecules/materials and performed routine characterization. L.R. 
performed TEM measurements. L.V. designed and performed the ss-NMR experiments at 16.4 T. Z.B. performed the ss-NMR experiments at 20 T. Results were analyzed by L.V. and C.C. Initial drafts were written by L.V. Further editing of the manuscript was conducted by L.V., J.M., Z.B., L.R., J.A.v.B. and C.C. All authors have given approval to the final version of the manuscript.

\section{Funding Sources}

Shell BV partially funded this work through a $\mathrm{PhD}$ grant that led to the development of $\mathrm{g}$ alumina nanocrystals. Z.B. was funded by an SNF grant.

\section{ACKNOWLEDGMENT}

J.M was funded by Shell BV. Andrew Horton and Sanders van Bavel (Shell BV) are acknowledged for scientific discussions during the development of $\gamma$-alumina nanocrystals. L.V. thanks Dr. René Verel and Dr. Alexander Yakimov for useful discussions on ss-NMR measurements. The authors also want to thank Prof. Alexander Barnes for access to the $850 \mathrm{MHz}$ magnet.

\section{REFERENCES}

(1) Euzen P.; Raybaud P.; Krokidis, N.; Toulhoat, H.; Le Loarer J.-L.; Jolivet J.-P.; Froidefond C., in: Handbook of Porous Solids, Wiley-VCH Verlag GmBH, Weinheim, Germany

(2) Busca, G. Structural, Surface and Catalytic Properties of Aluminas. Advances in Catalysis 2014, 57, ISSN 0360-0564, https://doi.org/10.1016/B978-0-12-800127-1.00003-5 
(3) Digne, M.; Sautet, P.; Raybaud, P.; Euzen, P.; Toulhoat, H. Hydroxyl groups on $\gamma$ Alumina Surfaces: A DFT Study. J. Catal. 2002, 211, 1-5, https://doi.org/10.1006/jcat.2002.3741

(4) Digne, M.; Sautet, P.; Raybaud, P.; Euzen, P.; Toulhoat, H. Use of DFT to achieve a rational understanding of acid-basic properties of $\gamma$-alumina surfaces. J. Catal. 2004, 226, 54-68, https://doi.org/10.1016/j.jcat.2004.04.020

(5) Wischert, R.; Laurent, P.; Copéret, C.; Delbecq, F.; Sautet, P. $\gamma$-Alumina: The Essential and Unexpected Role of Water for the Structure Stability and Reactivity of "Defect" Sites. J. Am. Chem. Soc. 2012, 134, 35, 14430-14449, https://doi.org/10.1021/ja3042383

(6) Busca, G. The surface of transitional aluminas: A critical review. Catal. Today 2014, 226, 2-13, https://doi.org/10.1016/j.cattod.2013.08.003

(7) Batsita A.T.F.; Wisser D.; Pigeon T.; Gajan D.; Diehl F.; Rivallan M.; Catita L.; Gay A.S.; Lesage A.; Chizallet C.; Raybaud, P. Beyond $\gamma-\mathrm{Al}_{2} \mathrm{O}_{3}$ crystallite surfaces: The hidden features of edges revealed by solid-state ${ }^{1} \mathrm{H}$ NMR and DFT calculations. J. Catal. 2019, 378, 140-143, https://doi.org/10.1016/j.jcat.2019.08.009

(8) Kaya C., He J.Y., Gu X., Butler E.G. Nanostructured ceramic powders by hydrothermal synthesis and their applications. Miropor Mesopor Mat. 2002, 54, 37-49, https://doi.org/10.1016/S1387-1811(02)00334-7

(9) Chen X.Y., Zhang Z.J., Li X.L., Lee S.W. Controlled hydrothermal synthesis of colloidal boehmite $\left(\gamma\right.$-AlOOH) nanorods and nanoflakes and their conversion into $\gamma-\mathrm{Al}_{2} \mathrm{O}_{3}$ nanocrystals. Solid State Commun. 2008, 145, 368-373, https://doi.org/10.1016/j.ssc.2007.11.033

(10) He T., Xiang L., Zhu S. Different nanostructures of boehmite fabricated by hyrothermal process: effect of $\mathrm{pH}$ and anions. CrystEngComm, 2009, 11, 1338-1342, $\underline{\text { https://doi.org/10.1039.b900447p }}$ 
(11) Zhang X., Cui W., Page K.L., Pearce C.I., Bowden M.E., Graham T.R., Shen Z., Li P., Wang Z., Kerisit S., N'Diaye A.T., Clark S.B., Rosso K.M. Size and Morphologoy Controlled Synthesis of Boehmite Nanoplates and Crystal Growth Mechanisms. Cryst. Growth Des. 2018, 18(6), 3596-3606, https://doi.org/10.1021/acs.cgd.8b00394

(12) Fujii T., Kawasaki S., Suzuki A., Adschiri T. High-Speed Morphology control of Boehmite Nanoparticles by Supercritical Hydrothermal Treatment with Carboxylic Acids. Cryst. Growth Des. 2016, 16, 1996-2001, https://doi.org/10.1021/acs.cgd.5b01584

(13) Li Z., Liu G., Li X., Qi T., Peng Z., Zhou Q. Effects of Cation on the Morphology of Boehmite Precipitated from Alkaline Solution by Adding Gibbsite as Seed. Cryst. Growth Des. 2019, 19, 3, 1778-1785, https://doi.org/10.1021/acs.cgd.8b01756

(14) Huang W., Liu G., Qi T., Li X., Zhou Q., Peng Z. Effects of pH and ions on the morphological evolution of boehmite prepared by hydrothermal treatment of ultrafine Bayer gibbsite. CrystEngComm, 2020, 22, 6983, https://doi.org/10.1039/d0ce00808g

(15) Venkatesh A.; Perras F.A.; Rossini A.J. Proton-detected solid-state NMR spectroscopy of spin-1/2 nuclei with large chemical shift anisotropy. J. Magn. Reson. 2021, 327, 106983, https://doi.org/10.1016/j.jmr.2021.106983

(16) De Souza Santos P., Vieira Coelho A.C. Hydrothermal Synthesis of Well-Crystallised Boehmite Crystals of Various Shapes. Mater. Res. 2009, 12 (4), 437-445, https://doi.org/10.1590/S1516-14392009000400012

(17) DeCanio E.C.; Edwards J.C.; Bruno J.W. Solid-State ${ }^{1}$ H MAS NMR Characterization of $\gamma$-Alumina and Modfied $\gamma$-Aluminas. J. Catal. 1994, 148, 76-83, https://doi.org/10.1006/jcat.1994.1187

(18) Taoufik M.; Szeto K.C.; Merle N.; Del Rosal I.; Maron L.; Trébosc J.; Tricot G.; Gauvin R.M.; Delevoye L. Heteronuclear NMR Spectroscopy as a Surface Selective Technique: A Unique Look at the Hydroxyl Groups of $\gamma$-Alumina. Chem. Eur. J. 2014, 20, 4038-4046, https://doi.org/10.1002/chem.201304883 
(19) Tsyganenko A.A.; Filimonov V.N. Infrared Spectra of Surface Hydroxyl Groups and Crystalline Sturcture of Oxides. J. Mol. Struct. 1973, 19, 579-589

(20) Knözinger H.; Ratnasamy P. Catalytic Aluminas: Surface Models and Characterization of Surface Sites. Catal. Rev.-Sci. Eng. 1978, 17(1), 31-70, https://doi.org/10.1080/03602457808080878

(21) Busca D.; Lorenzelli V.; Ramis G.; Willey R.J. Surface Sites on Spinel-Type and Corundum-Type Metal Oxide Powders. Langmuir 1993, 9, 1492-1499

(22) Feike, M.; Demco, D.E.; Graf, R.; Gottwald, J.; Hafner, S.; Spiess, H.W. Broadband Multiple-Quantum NMR Spectroscopy. J. Magn. Reson. 1996, 122(2), 214-221, https://doi.org/10.1006/jmra.1996.0197

(23) Saalwächter K.; Lange F.; Matyjaszewski K., Huang C.-F.; Graf R. BaBa-xy16: Robust and broadband homonuclear DQ recoupling for applications in rigid and oft solids up to the highest MAS frequencies. J. Magn. Reson. 2011, 212 (1), 204-215, https://doi.org/10.1016/j.jmr.2011.07.001

(24) Rossini A.J.; Hanrahan M.P.; Thuo M. Rapid acquisition of wideline MAS solid-state NMR spectra with fast MAS, proton detection and dipolar HMQC pulse sequences. Phys. Chem. Chem. Phys. 2016, 18, 25284, https://doi.org/10.1039.c6cp04279a

(25) Venkatesh A.; Hanrahan M.P.; Rossini A.J. Proton detection of MAS solid-state NMR spectra of half-integer quadrupolar nuclei. Solid State Nucl. Magn. Reson. 2017, 84, 171181, https://doi.org/10.1016/j.ssnmr.2017.03.005

(26) Szeto K.C.; Merle N.; Trébosc J.; Taoufik M.; Gauvin R.M.; Pourpoint F.; Delevoye L. Caveat on the Actual Robustness of Heteronuclear NMR Methods for Probing the Surface of $\gamma-\mathrm{Al}_{2} \mathrm{O}_{3}$ and Related Catalysts. J. Phys. Chem. 2019, 123, 12919-12927, https://doi.org/10.1021/acs.jpcc.9b02634 
(27) Hu B.; Trébosc J.; Amoureux J.P. Comparison of several hetero-nuclear dipolar recoupling NMR methods to be used in MAS HMQC/HSQC. J. Magn. Reson. 2008, 192, 112-122, https://doi.org/10.1016/j.jmr.2008.02.004

(28) Brinkmann A.; Kentgens A.P.M. Proton-Selective ${ }^{17} \mathrm{O}-{ }^{1} \mathrm{H}$ Distance Measurements in Fast Magic Angle Spinning Solid State NMR Spectroscopy for the Determination of Hydrogen Bond Lengths. J. Am. Chem. Soc. 2006, 128, 46, 14758-14759, https://doi.org/10.1021/ja065415k

(29) Wischert R.; Florian P.; Copéret C.; Massiot D.; Sautet P. Visibility of Al Surface Sites of $\gamma$-Alumina: A Combined Computational and Experimental Point of View. J. Phys. Chem. 2014, 118, 28, 15292-15299, https://doi.org/10.1021/jp503277m

(30) Malär A.A.; Völker L.A.; Cadalbert R.; Lecoq L.; Ernst M.; Böckmann A.; Meier B.H.; Wiegand T. Temperature-Dependent Solid-State NMR Proton Chemical Shift Values and Hydrogen Bonding. J. Phys. Chem. B 2021, 125, 23, 6222-6230, https://doi.org/10.1021/acs.jpcb.1c04061

(31) Le Caër G.; Bureau B.; Massiot D. An extension of the Czjzek model for the distributions of electric field gradients in disordered solids and an application to NMR spectra of ${ }^{71} \mathrm{Ga}$ in chalcogenide glasses. J. Phys.: Condens. Matter 2010, 22, 065402, https://doi.org/10.1088/0953-8984/22/6/065402 